\title{
Search strategies
}

\author{
With public understanding and academic enthusiasm for plant science dwindling, now is the time to take the \\ fascination for plants to the people.
}

W here are the next generation of plant scientists?

This is not a trivial question. Chances are that if you are reading this you already know how fascinating the lives of plants are. You know about their beauty and variety. You know how central they are to the continuation of life on Earth. You know too that the crises of starvation and malnutrition facing a growing number of the global population can only be alleviated by the breeding and engineering of improved crop species. You also appreciate how fulfilling a career in plant research is. But is any of this common knowledge? After all, plant research isn't rocket science, or a cure for cancer!

Since 2014, while the number of $\mathrm{PhDs}$ being awarded in the life sciences has increased each year (doubling in the United States between 1982 and 2012; ref. ${ }^{1}$ ), those in pure and applied plant sciences have remained flat. At the undergraduate level, pure plant biology degrees have become rare and only a handful of universities in the United Kingdom offer them. The last British student enrolled for a degree in botany over a decade ago; a pattern seen across the globe to varying extents.

Such side-lining of plant biology is not the result of any conspiracy - it is simply the free market at work. If high school students were crying out to study plant biology, then plant biology courses would exist to cater for them. One reason they are not is that plant science has such a low profile in the general media. Advances in science, technology, engineering and mathematics (STEM) subjects already have fairly low coverage in the non-specialist press, and plant work tends to be underexposed even within this niche. Media coverage also fails to reflect the most scientifically interesting or representative work. For example, when looking at studies published in Nature Plants, our all-time,top three most covered stories according to Altmetric.com are a study modelling the effect of future climate change on yields of barley ${ }^{2}$, a survey of mortality in Baobab trees $^{3}$, and last month's analysis of the flavour and climate resilience of Coffea stenophylla ${ }^{4}$. All are excellent studies, and made for attention-grabbing headlines such as 'Climate change will cause beer shortages', 'Why are some of Africa's oldest Baobab trees dying off?' and 'Future-proofing coffee in a warming world', but they are hardly representative of the preoccupations of most plant researchers.

However, we should not rush too quickly to judge others. A paper in this issue of Nature Plants shows that plant researchers themselves are not immune to unconcsious bias in what they find interesting. A survey of the literature relating to species from the Southwestern Alps finds that plants with more accessibile, more conspicuous and (preferably) blue flowers are more often the objects of research than their more typical dowdy and ground-hugging neighbours ${ }^{5}$.

I hesitate to quote the children's rights activist Marian Wright Edelman out of context but her famous saying, "you can't be what you can't see" is relevant here. Without prominent examples of plant scientists and their work, we cannot expect students to be enthused by the mysteries of plant life or be inspired to work on unravelling them.

The question of how to achieve such successful outreach initiatives is the subject of a recent white paper ${ }^{6}$ published in Plant Direct; a result of a symposium and workshop from November 2018, funded by the National Science Foundation and held at the University of California, Davis. This is an extensive exploration of the diverse opportunities and challenges that face anyone trying to communicate their private passions to a public audience. There is plenty of useful advice on how to tackle social media and podcasting, finding backing for initiatives and tailoring activities to particular audiences, as well as case studies of a number of mature and successful examples.

Disappointingly, the white paper does not look closely at the use of 'citizen science' projects, whereby anyone and everyone can become involved in a piece of scientific research. There are many opportunities for this in plant ecology, with one of the most successful examples being the Budburst project (https://budburst.org/) established by the Chicago Botanic Garden. This started in 2007 as a plant phenology project in which thousands of citizen scientists recorded the dates of emergence of leaves and flowers of numerous species across the United States. It has since expanded to include a suite of other projects and has developed a mobile phone app to aid identification and ensure consistency of data collection.

Whatever the form that outreach takes, it is important to engage the full diversity of our communities. The white paper cautions that "all scientists should receive implicit bias training in order to recognize unconscious prejudice" and discusses how even well-intentioned attempts to encourage participation can leave individuals from minority or marginalized groups with a strengthened sense of exclusion: "It's great that you're interested in plant science! Are you the first person in your family to consider going into science/going to college?".

Coincidentally, Beronda Montgomery recently discussed active ways of encouraging diversity in a scientific environment in a World View in Nature ${ }^{7}$. For her, the interactions and synergies of the plants and microorganisms studied in her laboratory are metaphors for achieving collective success in her team.

Scientific research is, at its heart, a human endeavour relying on the creativity of a multifaceted community. We cannot afford to wait for the diverse plant scientists of tomorrow to find us - we must reach out and find them.

Published online: 18 May 2021

https://doi.org/10.1038/s41477-021-00937-7

\footnotetext{
References

1. Jones, A. M. The planet needs more plant scientists. The Scientist https://go.nature.com/3eeoQtq (2014)

2. Xie, W. et al. Nat. Plants 4, 964-973 (2018).

3. Patrut, A. et al. Nat. Plants 4, 423-426 (2018).

4. Davis, A. P. et al. Nat. Plants 7, 413-418 (2021).

5. Adamo, M. et al. Nat. Plants https://doi.org/10.1038/s41477-02100912-2 (2021).

6. Friesner, J. et al. Plant Direct 5, e00316 (2021).

7. Montgomery, B. L. Nature 592, 327 (2021).
} 